\title{
REDUÇÃO DA MAIORIDADE PENAL
}

\author{
REDUCTION OF CRIMINAL MAJORITY
}

PEDRO HENRIQUE BATISTA SILVA ${ }^{1}$

ISSUE DOI: $10.21207 / 1983.4225 .460$

\section{RESUMO}

O presente artigo tem como principal escopo apresentar a todos os pontos positivos e negativos acerca do tema "A Redução da Maioridade Penal", não buscado demonstrar qual o melhor caminho a ser adotado, mas sim alguns aspectos importantes nesta grande discussão existente. Por meio de estudos doutrinários e pesquisas jurisprudenciais foi delimitado vários pontos importantes para que se possa chegar a uma solução plausível deste grande problema que enfrentamos hoje. É importante dizer que sendo ou não reduzida a idade penal vigente, serão necessárias mudanças comportamentais por parte de todos afim de uma sociedade mais justa, igual e solidário.

Palavras-chave: Maioridade penal. Redução. Criminalidade. Ato infracional. Menor infrator.

\section{ABSTRACT}

This article has as main aim to present all the positives and negatives about the theme "Reduction of Criminal Majority" not sought to demonstrate that the best way to be adopted, but some important aspects of this

1 Graduando em Direito pela Faculdade de Direito de Franca, cursando o último ano/período. 
major discussion. Through doctrinal studies and jurisprudential research was defined several important points so that we can reach a reasonable solution to this major problem we face today. It is important to say that whether or not reduced the current penal age will require behavioral changes by all in order to a more just, equal and supportive.

Keywords: Criminal. Majority. Reduction. Criminality. Infraction. Juvenile ofender.

\section{INTRODUÇÃO}

É notável o aumento maciço e desenfreado da violência no território brasileiro como um todo. Muitos acreditam ser consequência desta violência a falta de punição aos infratores, principalmente os menores.

A legislação vigente no país atualmente chama estes menores de inimputáveis, termo utilizado para denominar aquele que não pode ser apenado.

Quando o assunto é a sanção a ser aplicada ao criminoso devemos buscar o auxílio nas normas infraconstitucionais, como Código Penal, Código de Processo Penal dentre outros meios, isso se tratando de pessoa imputáveis, porém ao falarmos dos semi imputáveis ou inimputáveis devemos recorrer ao Estatuto da Criança e do Adolescente (ECA) (Lei ${ }^{\circ} 8069$ de 13 de julho de 1990), lei esta que ampara e baseia o tratamento que deve ser despendido a esses menores.

Atualmente muito tem se falado da redução da maioridade penal no sistema penal brasileiro, sendo esta tese defendida por grande parte da população do país. Porém como o tema é cercado de polêmica estudiosos da área afirmam ser esta mudança inconstitucional, por tentar diminuir o direito de uma parcela da sociedade, sendo que outra ala alega não ser um direito propriamente dito, e sim uma circunstância imposta pelo Estado.

Discussões à parte, o que continua a acontecer é o aumento da criminalidade, deixando cada vez mais pessoas a margem da sociedade, principalmente estes inimputáveis.

Seria a redução da maioridade penal o caminho para a diminuição da criminalidade? Colocar em uma mesma cela bandido com processo transitado em julgado e um menor em pleno desenvolvimento de seu caráter resolveriam este problema? A aplicação correta do Estatuto da 
Criança e do Adolescente (ECA), com as devidas alterações no mesmo, não seria uma alternativa para a melhoria do país? $\mathrm{O}$ investimento na educação e políticas de incentivo ao jovem não deve ser rediscutido?

\section{O MENOR}

A lei Brasileira utiliza a idade do agente para o classificar como menor. Antes da reforma de 1984, o Código Penal em seu art. 23 tratava os menores de 18 anos pela terminologia irresponsáveis. Eles eram assim chamados por não terem a idade mínima suficiente para lhes serem imputadas algum tipo de culpa sobre uma conduta ilícita.

Contudo, em 11 de novembro de 1984 foi sancionada a Lei 7.209/84 que trouxe significativas alterações para a seara do Direito Penal, implantando de uma vez por todas o instituto da inimputabilidade no cotidiano dos operadores do Direito. O atual art. 27 do Código Penal Brasileiro usa agora a terminologia penalmente inimputáveis ao invés de irresponsáveis.

Quando questionado o porquê da utilização da idade como parâmetro para a inimputabilidade a resposta é que foi adotado o critério biológico pelo legislador para esta distinção. A doutrina majoritária fala ser esta uma presunção absoluta, ou seja, alega ser o menor de 18 anos de idade incapaz de compreender os atos que comete por ter seu desenvolvimento psico-mental incompleto, não podendo ser imposta a este pena como se adulto fosse.

Por se tratar de presunção absoluta, não há de se falar aqui de prova em contrário, ou seja, quando o menor de 18 anos cometer algum tipo de delito, o simples fato do agente não ter a idade mínima necessária já o caracteriza como sendo inimputável, não podendo ser punido pelo Código Penal, pois não estará configurado sua imputabilidade, o que gera duras críticas ao sistema adotado.

Estas críticas se dão pelo fato de que não se pode generalizar a incapacidade do agente pelo fato de não ter 18 (dezoito) anos completos, alegando que por vezes esse menor está totalmente ciente do ato que pratica, mas se esconde atrás desta excludente de ilicitude afim de não ser penalmente responsabilizado ou até mesmo para proteger outros comparsas. 
Guilherme Nucci em sua obra, critica exatamente este fato, alegando ser o menor de 18 (dezoito) anos capaz de votar e assumir outros direitos, mas incapaz de ser sancionado penalmente:

Se o menor com mais de 16 anos e menos de 18 torna-se cidadão pelo direito de voto; se a mulher casada se emancipa, civilmente, com o casamento aos 16 anos; até uma lei chegou a ser aprovada (posteriormente vetada pelo Presidente da República) autorizando que o maior de 16 anos pudesse dirigir veículos, não se compreende que não possa responder pelos atos ilícitos que, por ventura, praticar. É uma concepção unilateral da cidadania, pois o agente torna-se cidadão pelo voto facultativo aos 16 anos, mas não tem o dever de responder pelos crimes eleitorais que eventualmente praticar. À primeira vista, considerando-se a garantia da cidadania do art. $1^{\circ}$ da Constituição Federal, e o art. 14 da mesma, no tocante à aquisição dos direitos políticos, verifica-se inconstitucionalidade na posição daqueles que defendem a permanência do critério biológico, com a idade fixada em 18 anos, a despeito do art. 228 da Constituição Federal, que não pode contrapor-se às regras de cidadania. ${ }^{2}$

Porém, a inimputabilidade não se restringe apenas ao agente menor de 18 anos que comete um delito, este instituto abrange outras excludentes de ilicitude como é o caso do art. 26 do Código Penal Brasileiro, onde é tratado do doente mental, do retardado ou do que tenha o desenvolvimento metal incompleto.

Para a verificação da higidez mental do agente que comete o delito e levado em conta os seguintes critérios: a) biológico: onde se verifica ser o agente doente mental, retardado, ou com incompleto desenvolvimento mental; b) psicológico: verifica se o agente compreende o caráter ilícito da medida que está tomando; c) biopsicológico: une-se os dois critérios anteriormente abordados para realização do caso específico.

${ }^{2}$ NUCCI, Guilherme de Souza. Código Penal Comentando, $13^{\text {a }}$ ed. rev., atual e ampl. São Paulo: Revista do Tribunais, 2012. p. 300. 
A respeito da saúde mental do agente Márcia Milhomens Sirotheau Corrêa assim explica:

O Código Penal de 1969, adotando o critério biopsicológico, continha disposição (art.33) que autorizava a imposição de pena ao indivíduo com idade entre dezesseis e dezoito anos, desde que este revelasse suficiente desenvolvimento psíquico para entender o caráter ilícito do fato e de determinar-se de acordo com esse entendimento. ${ }^{3}$

Assim como o Código Penal Brasileiro preleciona ser inimputável o menor de 18 anos, a Constituição Federal de 1988 em seu artigo 228 tratou de fixar também esta como sendo a idade mínima para que o agente de um fato ilícito seja penalizado, porém este agente não estará sujeito as normas do referido diploma e sim do Estatuto da Criança e do Adolescente - ECA.

O referido artigo de nossa Carta Magna estabelece: “art. 228. são penalmente inimputáveis os menores de 18 anos, sujeitos às normas da legislação especial".

Este limite biológico fixado pelo legislador da Constituição $\mathrm{Fe}$ deral de 1988 tem como base a Convenção da ONU de 20 de novembro de 1989, onde diz em seu art. 1": "Nos termos da presente Convenção, criança é todo o ser humano menor de 18 anos, salvo se, nos termos da lei que lhe for aplicável, atingir a maioridade mais cedo", contudo não foi este artigo uma imposição ao legislador brasileiro, tanto que o artigo 37 da referida Convenção diz ser possível a imposição de penas restritivas de liberdade a menores de 18 anos, ficando a cargo do legislador dos países signatários desta Convenção.

Porém não foi apenas isto que a Constituição Federal tratou a respeito da criança e do adolescente em seu texto, trouxe também garantias para que esses possam crescer, buscando transformar-se em seres humanos dignos e com um perfeito desenvolvimento psico-mental.

$\mathrm{O}$ art. 227 da CF/88 deixa claro que a família será a base para que a criança e o adolescente tenham um respaldo pleno no seu cresci-

${ }^{3}$ CORRÊA, Márcia Milhomens Sirotheau. Caráter fundamental da inimputabilidade na constituição, vol. I. Porto Alegre, Sergio Antonio Fabris Editor, 1998. p. 155. 
mento e desenvolvimento. Além do mais este artigo exterioriza, sem sombra de dúvida, a chamada Doutrina de Proteção Integral, conforme elucida Rodolfo Cesar Milano:

A questão da liberdade da criança e do adolescente foi amplamente abordada pelo Estatuto, dando suporte à relevância da opinião e expressão, crença e culto, esportes e diversão, participação da vida familiar, comunitária e política, bem como busca de refúgio, auxílio e orientação. ${ }^{4}$

Com base na Teoria acima mencionada podemos concluir que o grupo da criança e do adolescente é o mais protegido perante nossa Constituição, pois a eles devem ser destinado todo tipo de esforço para seu crescimento pleno, inclusive existem correntes da doutrina que defendem o não retrocesso da lei no tocante a redução da maioridade penal, pois além de toda essa proteção recebida pelo grupo mencionada o artigo 228 da Constituição Federal é tratado por esta mesma corrente da doutrina como cláusula pétrea, não podendo ser alterada por simples vontade do legislador.

Nesse sentido, raciocina Frederico Afonso Izidoro:

Entendo que o artigo 228 é uma cláusula pétrea, conforme artigo $60, \S 4^{\circ}$, inciso IV c/c artigo $5^{\circ}, \S$ $2^{\circ}$, tudo da constituição. Portanto, só seria possível alterar este direito individual através de uma nova constituição. Digo teoricamente, pois no âmbito dos direitos humanos, um direito humano alcançado não retroage (a irretroatividade é uma das características clássicas do Direito Internacional dos Direitos Humanos). ${ }^{5}$

\footnotetext{
${ }^{4}$ CESAR, Rodolfo Milano. Estatuto da criança e do Adolescente, comentado e interpretado. Livraria e editora Universitária de Direito, 1996. p. 37.

${ }^{5}$ IZIDORO, Frederico Afonso. Redução da Idade Penal: Impossibilidade. Jornal Carta Forense, julho de 2013.
} 
O ponto de vista do nobre doutrinador citado é o principal argumento para os defensores da não redução da maioridade penal, porém existe outra corrente que alega não ser cláusula pétrea o artigo citado, como preleciona o Promotor de Justiça Eduardo Del-Campo:

Entendemos que a fixação da idade de imputabilidade penal não constitui cláusula pétrea. No máximo, poder-se-ia afirmar que existe a necessidade de fixação de uma idade específica para a imputabilidade penal, ou seja, a Constituição Federal, adotou o critério biológico. Este não poderia ser alterado, porém, fica a cargo do legislador infraconstitucional que deverá observar a evolução da sociedade. ${ }^{6}$

Diante de tamanha discussão resta saber e verificar ponto a ponto de todo o discutido, se a redução da maioridade penal seria o melhor caminho para a deminuição da criminalidade em nosso País.

\section{$2 \quad$ ATO INFRACIONAL}

Após a promulgação do Estatuto da Criança e do Adolescente houve uma drástica mudança no tratamento despendido ao menor que venha a cometer algum tipo de delito. É sabido que os menores de 18 anos não praticam crime, ou seja, por serem inimputáveis, a terminologia usada para os atos ilícitos cometido é ato infracional, que busca de uma maneira menos agressiva demonstrar a prática de um crime pelo menor.

Com grande sabedoria Carlos Eduardo Barreiros Rebelo elucida:

Consciente de que a criança e o adolescente não cometem crimes, o legislador tratou de encontrar nomenclaturas que se revelassem como verdadeiros eufemismos para descrever a conduta do infrator, estabelecendo que ele não comete crime, mas sim

\footnotetext{
${ }^{6}$ DEL-CAMPO, Eduardo. Redução da Idade Penal: Possibilidade. Jornal Carta Forense, julho de 2013.
} 
ato infracional; tampouco está sujeito a pena, podendo ser-lhe aplicadas as chamadas medidas sócio educativas, em uma nítida suavização de ideias. $^{7}$

O que acontece na prática é que o Estatuto da Criança e do Adolescente aplicou o Principio Igualdade, consagrado na $\mathrm{CF} / 88$, onde diz ser dever do Estado tratamento igual para os iguais e desigual para os desiguais, ou seja, toda conduta caracterizada pela legislação comum como sendo crime ou contravenção penal para o ECA é um Ato Infracional, demonstrando que todo aquele grupo amparado por esta legislação especial não comete crime antes de completada a maioridade, por este motivo a pena a ele imposta será em forma de medida sócio-educativa e não punitiva como prevê o restante da legislação.

O professor Carlos Eduardo Barreiros Rebelo conceitua com grande lucidez o que é o Ato Infracional:

O conceito de ato infracional é descrito pelo artigo 103 do Estatuto como sendo a conduta descrita como crime ou contravenção penal. A criança, quando pratica um ato infracional, somente poderá ser submetida às medidas previstas no artigo 101 do Estatuto. ${ }^{8}$

Com isso conclui-se que não existe diferença entre condutas tipificadas como crime, contravenção penal e ato infracional, o que diferencia uma das outras é apenas a terminologia adotada, sendo algumas aplicadas aos maiores de 18 anos e outras aos menores de 18 anos.

Cabe ainda uma ressalva a respeito dos delitos. Será levado em conta para efeitos de penalização a idade do agente ao cometer o delito, ou seja, caso o agente tenha cometido o delito quando ainda menor (17 anos 11 meses e 29 dias) este será considerado ato infracional, mesmo sendo ele julgado depois de completar a maioridade. Isso se dá pois o ECA adotou a Teoria da Atividade, que diz ser punido com medida sócio-

\footnotetext{
${ }^{7}$ BARREIROS, Carlos Eduardo Rebelo. Maioridade penal e a polêmica acerca de sua redução. $1^{\mathrm{a}}$ ed. Belo Horizonte, IUS editora, 2010. p. 36.

${ }^{8}$ Ibidem.
} 
educativa todo aquele agente menor de idade que tenha cometido um ato infracional, mesmo sendo ele julgado após completar a maioridade, conforme elucida Nazir David Milano Filho.

Acolheu-se a teoria da atividade do ato, o que significa que, praticado o ato infracional, as medidas sócio educativas serão, em caso de comprovação da prática ilícita, instaurado o processo contraditório, aplicadas ao adolescente que ainda não tenha alcançado a idade de dezoito anos de idade, perdurando a medida, ainda, até esse limite etário, havendo como únicas exceções as medidas sócio educativas pertinentes à semiliberdade e internação, que poderão ser aplicadas mesmo que o adolescente já tenha alcançado a faixa dos dezoito anos de idade. $^{9}$

Devido a idade do infrator, ocorrerá a apuração do ato infracional para a verificação da prática do delito pelo menor, onde deverá ser providenciada de pronto a apresentação deste a autoridade judiciária. Há quem diga ser competente para este ato o Juiz de Menores, mas independentemente de quem for, este menor deverá ser levado a presença do responsável para que seja tomada as devidas medidas em relação a investigação do delito. Contudo não será uma investigação comum, ao realizar a apreensão, a autoridade policial deverá avisar imediatamente a autoridade judiciária competente, a família do menor apreendido ou a pessoa indicada por ele.

É de suma importância lembrar que a responsabilidade de avisar a família do menor ou pessoa por ele indicada, bem como a autoridade judiciária responsável é da autoridade policial.

Ainda sobre os procedimentos adotados pelo Estatuto da Criança e do Adolescente, podemos destacar aqui os casos em que o ato infracional é cometido com violência ou grave ameaça à pessoa. Neste caso dispõe o artigo 173 do aludido diploma o que deverá ser seguido pela autoridade polícia:

9 MILANO, Nazir David Filho. Estatuto da criança e do Adolescente, comentado e interpretado. Livraria e editora Universitária de Direito, 1996. p. 108. 
Art. 173. Em caso de flagrante de ato infracional cometido mediante violência ou grave ameaça à pessoa, a autoridade policial, sem prejuízo do disposto nos artigos 106, parágrafo único e 107, deverá:

I - Lavrar auto de apreensão, ouvidos as testemunhas e o adolescente;

II - apreender o produto e os instrumentos da infração;

III - requisitar os exames ou perícias necessárias à comprovação da materialidade e autoria da infração.

Parágrafo único. Nas demais hipóteses de flagrante, a lavratura do auto poderá ser substituída por boletim de ocorrência circunstanciado. ${ }^{10}$

Caso o ato infracional se enquadre no acima exposto o menor infrator estará sujeito as medidas sócio educativas constantes no art. 112 do Estatuo da Criança.

Art. 112. Verificada a prática de ato infracional, a autoridade competente poderá aplicar ao adolescente as seguintes medidas:

I - advertência;

II - obrigação de reparar o dano;

III - prestação de serviços à comunidade;

IV - liberdade assistida;

$\mathrm{V}$ - inserção em regime de semi-liberdade;

VI - internação em estabelecimento educacional;

VII - qualquer uma das previstas no art. 101, I a VI.

$\S 1^{\circ}$ A medida aplicada ao adolescente levará em conta a sua capacidade de cumpri-la, as circunstâncias e a gravidade da infração.

$\S 2^{\circ}$ Em hipótese alguma e sob pretexto algum, será admitida a prestação de trabalho forçado.

$\S 3^{\circ}$ Os adolescentes portadores de doença ou deficiência mental receberão tratamento individual e especializado, em local adequado às suas condições.

10 Estatuto da Criança e do Adolescente, disponível em: <http://www.planalto.gov.br/ccivil_03/leis/18069.htm>. Acesso em: 24 de maio de 2016. 


\section{ASPECTOS FAVORÁVEIS E CONTRÁRIOS À REDUÇÃO DA MAIORIDADE PENAL}

Quando se trata do tema "A Redução da Maioridade Penal" surgem os mais variados posicionamentos possíveis e muitos deles são tirados de um senso comum, o qual por vezes não expressa a realidade do pais. Para a abordagem deste tema é necessário analisar os mais diversos aspectos, sejam eles favoráveis ou desfavoráveis, o sistema carcerário brasileiro e os recursos destinados para a reeducação do jovem infrator. Lembrando que não será feito aqui um estudo conclusivo do que se deve fazer para melhorar ou aumentar a qualidade da segurança pública e sim expor de um modo geral os mencionados aspectos in casu.

Iniciaremos aqui pela corrente que é contrária a redução da maioridade penal. Os defensores desta corrente sustentam que a falta de investimento por parte do governo, principalmente no que diz respeito ao sistema carcerário brasileiro, gerará presos ainda mais revoltados e violentos, não sendo este o melhor caminho a ser seguido. Defendem ainda que se o jovem infrator for beneficiário de uma política de ressocialização correta, este poderá ser reinserido no mercado de trabalho, possibilitando por tanto sua saída em definitivo da vida delituosa, enquanto se for jogado em uma cela, junto a dezenas de presos adultos, que não recebem um mínimo de respaldo do Estado, poderá sair de lá pior que entrou, fazendo com que sua formação intelectual sofra um dano irreparável.

Sobre o tema nos ensina Carlos Eduardo Barreiros Rebelo:

Vale ressaltar, ainda, que reduzir a maioridade penal não soluciona os problemas referentes ao crescimento da criminalidade, uma vez que, como dito anteriormente, a escalada da violência se deve muito mais a problemas sociais do que problemas policiais. Some a isso o fato de que as cadeias públicas, os presídios, não possuem vagas capazes de receber esse contingente de presos que seria advindo da redução da maioridade penal, uma vez que é notório que o sistema está superlotado, não 
havendo sequer como dar vazão aos presos maiores de 18 anos. $^{11}$

Outro pilar dos defensores da não redução está no investimento a educação. Está cada dia mais visível que se estes adolescentes contassem com um sistema de ensino sério, o qual disponibilizasse para eles recursos visando o verdadeiro aprendizado, muitos não ingressariam nesse mundo sombrio dos crimes, até porque a grande maioria dos delitos não contam com a participação do menor.

Alude sobre o tema Jomar Moreno:

A sociedade precisa saber, que o foco não pode ser apenas no aumento da punição, pois paralela à punição é preciso haver educação, e paralela à educação é necessário investir na ressocialização para que apenados sejam inseridos na sociedade". "Não devemos discutir pena maior ou menor em cima de notícias de jornais. Temos que discutir em cima de estatísticas e os crimes violentos praticados por menores não chegam a $0,2 \%$ do total. ${ }^{12}$

Outro aspecto que deve ser aqui tratado é o rótulo de expresidiário que o menor ganharia caso fosse condenado por um crime como se imputável fosse. Esse rótulo com toda certeza refleteria na reinserção do jovem na sociedade e no mercado de trabalho, pois como é sabido o preconceito que a sociedade tem com os apenados ainda é grande, sendo isto uma barreira e uma dificuldade para aqueles que tem seus nomes escritos no rol dos culpados, por isso este jovem poderia facilmente ser pedido para a vida do crime.

Sobre este preconceito nos ensina Evandro Lins e Silva:

${ }^{11}$ BARREIROS, Carlos Eduardo Rebelo. Maioridade penal e a polêmica acerca de sua redução. $1^{\text {a }}$ edição. Belo Horizonte: IUS editora, 2010. p. 68.

12 MOREnO, J. A. Conselheiro da Ordem dos advogados do Brasil - seção DF na primeira audiência do ciclo de debates sobre a violência urbana realizado pela comissão de Direitos Humanos e Legislação participativa (CDH) em 22 de fevereiro de 2007. 
Os egressos do cárcere estão sujeitos a uma outra terrível condenação: - o desemprego. Legalmente, dentro dos padrões convencionais, não podem viver ou sobreviver. A sociedade que os enclausurou sob o pretexto hipócrita de reinseri-los depois em seu seio, repudia-os, repele-os, rejeita-os. Deixa, aí sim, de haver alternativa, o ex-condenado só tem uma solução: - incorporar-se ao crime organizado. ${ }^{13}$

Outro pilar dos defensores da não redução da maioridade penal é a manutenção do Estatuto da Criança e do Adolescente no sentido de aumentar a pena aplicada aos jovens infratores, tendo como principal pedido a majoração das medidas sócio educativa de caráter privativo de liberdade. Atualmente o jovem infrator poderá ficar no máximo 03 (três) anos internado segunda o ECA, porém muitos operadores do direito lutam para que esse período seja aumentado, inclusive existe projetos para que isso aconteça, tentando assim fazer com estas medidas tenham real serventia e sirvam talvez de aprendizado para aquele que cometer algum tipo de ilícito.

Carlos Eduardo Rebelo Barreiros tem a seguinte opinião sobre o tema:

O escopo principal é majorar as sanções para os atos infracionais considerados leves, impondo a eles o período máximo de três anos, enquanto para os graves, o prazo de três anos seria o mínimo e, para os equiparados a hediondos, o prazo mínimo chegaria a 5 anos. Seria possível, ainda, proceder a uma reavaliação a cada três anos, que poderia acarretar uma redução ou ampliação do tempo de internação, levando-se em consideração, para tanto, o comportamento do menor. ${ }^{14}$

Porém, mesmo com toda aclamação por mudanças no referido Estatuto não é possível ainda se chegar a um consenso no quesito tempo

\footnotetext{
${ }^{13}$ SILVA, Evandro Lins e. De Beccaria a Filippo Gramatica, in sistema penal para o terceiro milênio. 4. ed. Rio de Janeiro: Revan, 2011. p. 40.

${ }^{14}$ BARREIROS, Carlos Eduardo Rebelo. Maioridade penal e a polêmica acerca de sua redução, $1^{a}$ edição. Belo Horizonte: IUS editora, 2010. p. 70.
} 
de internação do jovem, caso tais mudanças fossem aprovadas.O que se busca realmente é que caso seja tomada alguma decisão está seja justa e sua aplicação não venha a prejudicar nenhum membro da sociedade.

Sobre as mudanças no período de internação do jovem infrator explica Álvaro Mayrink da Costa:

Acredito que, para uma reforma legislativa, seria prudente questionar que os adolescentes na faixa de 16 a 18 anos, que possa presumir discernimento, que tivessem cometido injustos hediondos ou a eles equiparados, submetidos a exame criminológico, poderiam ter um regime de internação máximo até 10 (dez) anos, em unidades especiais para jovens infratores. Sendo tal internação a título de medidas sócio educativas de caráter excepcional sob a jurisdição de juízes da infância e da juventude. ${ }^{15}$

As mudanças antes tratadas têm uma boa aceitação entre grande parte dos juristas, porém existe outras correntes que não concordam com estas alterações, segundo os defensores destas correntes a redução da maioridade penal é algo cada dia mais necessário no Brasil. Segundo os adeptos dessa corrente, a redução da maioridade penal deveria ser para 16 anos já outros vão além e diz que a redução deveria ser para 14 anos, pois segundo eles, só assim o jovem infrator seria realmente punido e deixaria de cometer delitos.

O principal argumento desta corrente é o de que o Código Penal Brasileiro não está em conformidade com a realidade da atual população do país, já que sua redação data de 1940, quando o discernimento do adolescente era realmente reduzido. Já nos dias de hoje, com tantas informações ao alcance dos menores é impossível, segundo os defensores desta corrente, alegar falta de conhecimento sobre o que é ou não é ilícito.

Além de todo o antes alegado, esta corrente diz que o jovem é constantemente estimulado a cometer ou assumir qualquer tipo de delito que venha a ocorrer, isto acontece pois eles sabem que mesmo lhe sendo atribuída a culpa por tal crime, seu nome estará limpo de antecedentes criminais e nenhum tipo de sanção recairá sobre sua pessoa.

15 COSTA, A. M. da. Direito Penal, Parte Geral. 8. Ed Rio de Janeiro: Ed. Forense, 2009. (v.2). p. 1234. 
Carlos Eduardo Rebelo Barreiros que é contra a redução da maioridade penal, rebate estes argumentos:

Deve ser questionado, como contraponto ao raciocínio esposado, se tal impunidade ou mesmo se tal inconsequência é inerente tão somente aos menores de 18 anos ou 21 anos? Como ponto de observação, deve-se mencionar que apenas $15 \%$ dos crimes são praticados por menores de 21 anos. Utilizar a redução da maioridade penal como solução para a criminalidade juvenil, sem enfrentar os graves problemas sociais que se revelam como causadores maiores da violência, revela-se em um raciocínio meramente utilitarista. ${ }^{16}$

Com isso fica claro que o que se deve buscar antes de realizar ou não a redução da maioridade penal no sistema penal brasileiro é olhar para a sociedade de um modo geral e refletir se o simples aumento das penas impostas aos criminosos irão sanar os graves problemas sociais que o pais enfrenta atualmente ou se os investimentos em saúde, educação e outros requisitos básicos solucionariam definitivamente essas deficiências.

\section{A REDUÇÃO DA MAIORIDADE PENAL}

Como já citado aqui, é notável o aumente da criminalidade em nosso atual cenário. Qualquer cidadão que tem acesso a pelo menos um meio de comunicação em massa pode notar este drástico aumento na violência, principalmente dos chamados crimes hediondos, que por vezes é cometido por crianças ou adolescentes, ainda protegidos pelo Estatuto da Criança e do Adolescente.

$\mathrm{O}$ fato de crianças e adolescente participarem destes delitos traz à tona a velha discussão a respeito da redução da maioridade penal, gerando, portanto, uma comoção social muito grande, onde parte da popula-

BARREIROS, Carlos Eduardo Rebelo. Maioridade penal e a polêmica acerca de sua redução, $1^{a}$ edição. Belo Horizonte: IUS editora, 2010. p. 71. 
ção diz ser esta a solução para a diminuição da criminalidade atual enquanto outra parcela da população discorda deste ponto de vista.

Com isso, muito se tem questionado a atual legislação que tutela o direito das crianças e dos adolescentes, alegando que o Estatuto em vigor traz consigo um espírito protecionista, o que provoca ainda mais sensação de impunidade ao jovem infrator e uma insegurança para o cidadão de bem.

O professor Fernando Capez, defensor da redução da maioridade penal assim se posiciona:

O Estatuto da Criança e do Adolescente (ECA) é um afronto jurídico, e principalmente, um atentado à justiça social. Tal Estatuto incentiva a criminalidade através da impunidade dos criminosos menores de idade, já que o ECA tem o despudor de proibir que a divulgação de seus nomes, e que suas fotos só podem ser estampadas mediante uma tarja de proteção ${ }^{17}$

Com a criminalidade cada dia mais alta e os delitos extremamente bárbaros sendo cometidos perante os olhos da sociedade, a população em geral não deve ater-se apenas as críticas a atual legislação e sim se esforçar para conter, juntamente com a polícia e os órgãos competentes esse drástico cenário atual. Porém para isso ocorrer é necessária uma mudança da sociedade como um todo, pois como já antes citado, grande parte da população insiste em achar que a prisão é o remédio para a criminalidade mas esquecem que este crime foi gerado por um problema anterior, que inclui a educação de péssima qualidade concedida pelo poder público, assim como o suporte dado as crianças, adolescentes e suas famílias pelos governantes do país.

Diante deste grave problema social que assola o pais deve-se buscar compreender o porquê do cometimento destes delitos e não simplesmente transferir a culpa afim de livrar-se dela. Unir menores infratores com maiores delinquentes seria uma solução um tanto quanto precipitada, pois esta ação poderia trazer danos irreversíveis para este menor, que por estar em pleno desenvolvimento de sua capacidade psíquico men-

${ }^{17}$ CAPEZ, F. Direito Penal - Parte Geral. 2 ed. São Paulo: Editora Saraiva, 2001. p. 49. 
tal poderia ser afetado de tal maneira que sua ressocialização ficaria extremamente comprometida ao ser preso em uma unidade prisional convencional, a qual não oferece o mínimo de suporte para a busca de sua melhoria, pois cada dia mais fica claro que o país não conta com um sistema prisional adequado para a ressocialização do delinquente. É fato que os investimentos realizados não buscam de fato beneficiar a população carcerária, isso nos mostra que as unidades prisionais servem apenas para depositar os apenados e não busca tirá-los da vida criminosa.

Diante deste fato resta claro que encarcerar menores não é a solução para diminuir a criminalidade, o que realmente precisamos é a apresentação de projetos visando maior rigorosidade na penas e medidas sócio educativas aplicadas, para que assim se tenha maior sucesso na busca de melhorias para a população de um modo geral, devendo também a família como base desse jovem, ser sempre ativa, na intenção de mostrar para o jovem que o melhor caminho a ser seguido não será o crime.

\section{CONSIDERAÇÕES FINAIS}

O tema "A Redução da Maioridade Penal" tratada neste artigo já é a tempos discutida tanto pelos governantes do país como pela população de um modo em geral, divergindo inclusive opiniões em vários âmbitos, pois cada dia mais os noticiários mostram os mais diversos casos de crimes que por vezes é cometido por menores. O fato deste aumento se dá, pois, muitos jovens vivem cada dia mais as margens da sociedade, instalando-se assim um verdadeiro caos social no país, caos este que só poderá ser cessado com investimento principalmente na área da educação e conscientização dos mais necessitados.

Fica nítido que muitas vezes os crimes são cometidos ou tem sua autoria assumidos por crianças e adolescentes pois a chance de não serem devidamente punidos é grande e a sensação de impunidade ainda maior em nosso país, principalmente por parte da população. Porém com este estudo aqui realizado ficou demonstrado que impunidade é diferente de inimputabilidade, enquanto este último faz referência a elemento processual, que é a aplicabilidade de pena para àqueles com 18 anos completos e nenhum tipo de impedimento o outro faz menção a falta de punição por parte do Estado para o infrator, o que não acontece, pois aquele que comete ato delituoso sempre é apenado em maior ou menor grau, depen- 
dendo do crime que cometeu e talvez esteja aqui a grande reclamação da população, pois acham que as penas aplicadas a esses menores são insuficientes para as suas reabilitações.

Através dos temas aqui tratados ficou claro que nosso sistema carcerário não é digno de nenhum tipo de qualificação, pois estão totalmente falidos e sucatiados, além de serem falhos; isso se dá pela falta de investimento por parte dos governos. Além do mais, é notável que o preso ao ingressar neste sistema não sai de lá recuperado pois não existe programas adequados para isso, fazendo assim com que o preso saia sem nenhum estímulo para deixar a vida delituosa e ainda com um rótulo de ex-presidiário que por si só já o atrapalhará em sua reinserção na sociedade e mercado de trabalho. Então podemos deduzir que se menores infratores fossem inseridos num mesmo habitat sem condições de recuperação estes seriam levados para o mesmo caminho dos maiores, demonstrando assim que reduzir a maioridade penal não é o caminho para diminuir a violência, até por que é ínfima a participação de menores em crimes bárbaros.

O motivo pelo qual estes jovens não seriam recuperados não é apenas culpa do sistema carcerário brasileiro, se dá também pois estes infratores estão em uma fase de pleno desenvolvimento psico-mental, sendo ainda nessa fase facilmente influenciados por outras pessoas, tendo em vista não terem ainda desenvolvido totalmente seu caráter, mostrando assim não ser o melhor caminho a imposição de duras penas a estes menores. Por mais que por diversas vezes estes infratores tem a consciência de seus atos não parece ser plausível apená-los antes de tentar reeduca-los e reinserir na sociedade.

A saída mais óbvia seria dar a todos chances iguais, sendo isso possível através de investimento por parte do governo, pois aquele que tem uma família estruturada, acesso a saúde e educação de qualidade, cultura e lazer não pode ser comparado ao jovem que vive às margens da sociedade e não conta com as mesmas oportunidades.

Com isso concluo aqui que a redução da maioridade penal não é o caminho correto a ser seguido, pois, impor penas a menores infratores e fazer com que estes a cumpram juntamente a criminosos adultos só poderá ter como resultado uma piora do menor infrator que foi preso, uma vez que a proximidade com criminosos e o consequente distanciamento de suas famílias apenas resultará em desabono para estes menores. Em contrapartida não parece ser justa a pena máxima de 03 (três) anos atribuída 
àquele jovem que cometeu crime hediondo com requinte de crueldade, devendo ocorrer sim mudanças no Estatuto da Criança e do Adolescente no sentido de se mostrar mais severos quando os crimes forem cometidos com as características antes já citadas.

\section{REFERÊNCIAS BIBLIOGRÁFICAS}

BARREIROS, Carlos Eduardo Rebelo. Maioridade Penal e a polêmica acerca de sua redução. Belo Horizonte: IUZ Editora. 2010.

CAPEZ, F. Direito Penal - Parte Geral. 2 ed. São Paulo: Editora Saraiva, 2001.

CESAR, Rodolfo Milano. Estatuto da criança e do Adolescente, comentado e interpretado. Livraria e editora Universitária de Direito, 1996.

COSTA, A. M. da. Direito Penal, Parte Geral. 8. Ed. Rio de Janeiro: Ed. Forense, 2009. (v.2)

DEL-CAMPO, Eduardo. Redução da Idade Penal: Possibilidade. Jornal Carta Forense, julho de 2013.

Estatuto da Criança e do Adolescente, disponível em: http://www.planalto.gov.br/ccivil_03/leis/18069.htm. Acesso em: 01 de agosto de 2017.

IZIDORO, Frederico Afonso. Redução da Idade Penal: Impossibilidade. Jornal Carta Forense, julho de 2013.

MILANO, Nazir David Filho. Estatuto da criança e do Adolescente, comentado e interpretado. Livraria e editora Universitária de Direito, 1996.

MORENO, J. A. Conselheiro da Ordem dos advogados do Brasil - seção DF na primeira audiência do ciclo de debates sobre a violência urbana realizado pela comissão de Direitos Humanos e Legislação participativa (CDH) em 22 de fevereiro de 2007.

NUCCI, Guilherme de Souza, Código Penal Comentando, $13^{\mathrm{a}}$ ed. rev., atual e ampl.. São Paulo: Editora Revista do Tribunais, 2012.

SILVA, Evandro Lins e. De Beccaria a Filippo Gramatica, in sistema penal para o terceiro milênio. 4. ed. Rio de Janeiro: Revan, 2011. 